\title{
PENGUKURAN KINERJA JURNAL ILMIAH TERAKREDITASI DI BATAN (ANALISIS BIBLIOMETRIK) ${ }^{1}$
}

\author{
Noeraida $^{1}$, Ajie Noorseto ${ }^{2}$ \\ 1,2Pusat Pendayagunaan Informatika dan Kawasan Strategis Nuklir \\ Badan Tenaga Nuklir Nasional, Serpong Tangerang Selatan \\ e-mail: noerda@batan.go.id, akira@batan.go.id
}

\begin{abstract}
ABSTRAK
Pegukuran kinerja jurnal ilmiah perlu dilakukan untuk mengevaluasi dan meningkatkan kualitas mutu, kuantitas serta dampak ilmiah bagi pelaku litbang. Kajian ini bertujuan mengevaluasi kinerja jurnal ilmiah terakreditasi di BATAN untuk meningkatkan kualitas pengelolaan jurnal menjadi lebih optimal. Metode yang digunakan analisis bibliometrik. Sumber data diperoleh dari portal jurnal pada http://jurnal.batan.go.id. Pemrosesan dan analisis data menggunakan Microsoft Excel, Publish or Perish Software (PoP) dan VOSviewer. Hasil kajian menunjukan semua jurnal memiliki tingkat keberkalaan yang baik. Terdapat 4 judul jurnal yang belum terindeks pada DOAJ. Penulis yang paling produktif adalah Wisnu Ari Adi, dan yang paling banyak disitasi adalah S. Hartanto dan Ratnawati. Hasil analisis metrik jurnal menunjukan dampak ilmiah yang diukur dengan jumlah artikel yang disitasi termasuk dalam kategori tinggi. Jurnal yang paling produktif dan banyak disitasi adalah J. Sains Materi Indonesia, namun jurnal yang memiliki rasio jumlah sitasinya paling tinggi adalah jurnal Urania sebesar 1,44. Visualisasi kolaborasi menunjukkan adanya kolaborasi antar penulis yang didapat dari delapan jurnal terakreditasi.
\end{abstract}

Kata kunci: jurnal ilmiah, akses terbuka, analisis sitasi, bibliometric, aplikasi Publish or Perish

\begin{abstract}
Measurement of the performance of scientific journals needs to be done to evaluate and improve the quality, quantity, and scientific impact of R\&D practitioners. This study aims to evaluate the performance of accredited scientific journals in BATAN to improve the quality of journal management more optimally. The method used is bibliometric analysis. Data sources were obtained from the journal portal at http://jurnal.batan.go.id. Data processing and analysis using Microsoft Excel, Publish or Perish Software (PoP) and VOSviewer. The results of the study show that all journals have a good degree of scale. There are 4 journal titles that have not been indexed in DOAJ. The most productive writer is Wisnu Ari Adi, and the most cited are S. Hartanto and Ratnawati. Journal metric analysis results show the scientific impact measured by the number of articles cited included in the high category. The most productive and cited journal is J. Sains Materi Indonesia, but the journal that has the highest ratio of the number of cytities is Urania at 1,44. Visualization of collaboration shows the collaboration between authors obtained from eight accredited journals.
\end{abstract}

Keyword: scientific journals; open access; citation analysis; bibliometrics; Publish or Perish Software

${ }^{1}$ Disampaikan pada Webinar dan Knowledge Sharing Kepustakawanan Forum LPNK Ristek pada tanggal 5 Mei 2020 di PDDI-LIPI Jakarta 


\section{PENDAHULUAN}

Terdapat berbagai produk litbangyasa dalam berbagai bidang yang telah dihasilkan oleh Badan Tenaga Nuklir Nasional (BATAN) sampai saat ini seperti bidang pertanian, kesehatan, industri, dan lingkungan, dan lainnya. Dalam 5 (lima) tahun mendatang BATAN akan mengutamakan usaha yang optimal untuk melakukan hilirisasi hasil litbang iptek nuklir agar dapat bermanfaat untuk masyarakat (BATAN, 2019). Untuk mendukung program hilirisasi, perlu dilakukan diseminasi terhadap hasil yang sudah diperoleh dengan mempublikasikan hasil riset melalui jurnal ilmiah nasional terakreditasi maupun internasional. Oleh karena itu publikasi artikel pada jurnal ilmiah dan hilirisasi hasil penelitian saling berkaitan. Jurnal ilmiah atau terbitan berkala adalah jenis sumber informasi primer yang sangat dibutuhkan dan berperan penting dalam mendiseminasikan hasil penelitian. Jurnal yang memiliki kualitas mutu yang baik serta konsisten terbit secara teratur, membantu para peneliti sebagai penghasil temuan dalam iptek dengan terlebih jurnal yang memiliki kualitas yang baik karena berperan besar selain untuk dukungan literatur juga untuk mempublikasikan hasil riset dengan cepat (Maryono dan Junandi, 2012). Selain itu, jurnal ilmiah diperlukan selain untuk memasyarakatkan hasil penelitian juga memperlihatkan profesionalisme peneliti itu sendiri (Nashihuddin dan Aulianto, 2016).

Sementara fenomena open access (OA) yang didefinisikan sebagai sumber rujukan atau bahan perpustakaan dalam bentuk digital, daring (online), bebas biaya, pembatasan hak cipta serta lisensi (Prasetyawan, 2017), telah ada sejak berkembangnya internet di dunia. Salah satu implementasi OA adalah pengelolaan jurnal ilmiah yang harus diterbitkan secara daring. Menurut Lukman, et al. (2019), pengelolaan jurnal di Indonesia juga mengalami perubahan, diinisiasi oleh PDII LIPI dengan mengembangkan aplikasi yang dapat digunakan untuk mengelola jurnal ilmiah agar lebih efektif dan efisien yang saat ini dikenal dengan open journal system (OJS). Hal ini menurut Aulianto, et al (2019), menjadikan terbitan berkala sebagai media untuk menyalurkan informasi kepada masarakat semakin berkembang dengan pesat. Dengan dukungan teknologi yang juga semakin maju, dalam pengelolaannya menjadi sangat mudah dan praktis, maka semakin banyak jurnaljurnal baru yang diterbitkan secara elektronik.

Pada Permenristekdikti Nomor 9 Tahun 2018 yang menjadi rujukan dalam mengusulkan akreditasi jurnal ilmiah, salah satu persyaratan utama adalah memiliki manajemen yang efektif dan efisien yang melakukan pengelolaan jurnal secara online menggunakan aplikasi khusus untuk pengelolaan jurnal. Pengelolaan dimulai sejak pendaftaran pengguna, pengiriman atau submit makalah, review, penyuntingan sampai penerbitan serta dapat memantau sitasi dan jumlah pengguna yang mengunjungi portal jurnal. Akreditasi jurnal ilmiah saat ini berlaku 5 (lima) tahun (Kementrian Riset Teknologi dan Pendidikan Tinggi, (2018). Aplikasi untuk pengelolaan jurnal salah satunya adalah OJS, dapat digunakan untuk pengelolaan dan penerbitan jurnal, dapat dijalankan dengan mudah, lebih fleksibel dan pengguna dapat mengunduh makalah yang diperlukan secara gratis.

Jurnal ilmiah terakreditasi adalah jurnal yang telah memperoleh pengakuan resmi atas penjaminan mutu ilmiah melalui kewajaran penyaringan naskah, kelayakan pengelolaan, dan ketepatan waktu penerbitan terbitan berkala ilmiahnya (Nashihuddin dan Aulianto, 2016). Jumlah yang sudah memiliki ejurnal 36.000, sedangkan jurnal yang terakreditasi sampai dengan November 2019 sebanyak 3.463 judul jurnal 
(Lukman, 2019). Jumlah tersebut harus diikuti dengan peningkatan kinerja dengan kualitas dan kuantitas jurnal yang perlu dievaluasi khususnya oleh pengelola jurnal. Hal ini dilakukan agar artikel-artikel tidak semuanya diajukan ke jurnal di luar negeri saja, tetapi juga ke jurnal ilmiah yang diterbitkan di Indonesia.

Salah satu indikator jurnal ilmiah yang bermutu (terakreditasi) adalah mempunyai sumbangan bagi kemajun ilmu, yang dapat diukur dengan seberapa besar kontribusi jurnal dan artikel-artikel yang telah diterbitkan untuk kemajuan iptek dan penyelesaian masalah di bidang keilmuan masing-masing sangat nyata, nyata dan kurang nyata (Aulianto, et al., 2019). Strategi untuk meningkatkan mutu kualitas jurnal terakreditasi nasional adalah mempersiapkan jumlah sitasi artikel (Nashihuddin dan Aulianto, 2016). Analisis sitasi dilakukan untuk menghitung total kuantitas sebuah artikel jurnal yang dikutip oleh artikel jurnal yang lain. Sedangkan Impact Factor (IF) diaplikasikan untuk mengukur rata-rata artikel yang dimuat dalam sebuah publikasi jurnal yang disitasi dalam suatu periode tahunan tertentu. Teknik untuk menghitung total jumlah tulisan yang dipublikasikan ke dalam jurnal dan jumlah sitasi pada tulisan tersebut dikenal dengan nama bibliometrik (Prasetyawan, 2018).

Angka dan jumlah sitasi suatu jurnal ilmiah dapat diperoleh dengan mendaftarkan ke mesin pengindeks seperti Google Scholar, agar jumlah sitasi per artikel, jumlah total sitasi, h-index, iindex dan beberapa informasi terkait dapat dilihat. Google Scholar adalah mesin pengindeks yang berfungsi sebagai indicator kinerja penulis untuk karya tulis makalah, buku, dan lainnya. Salah satu cara untuk mengambil dan menganalisis serta menyajikan sitasi adalah dengan menggunakan aplikasi Publish or Perish Software (PoP). Aplikasi ini dapat mengambil, menganalisis dan menyajikan sitasi dengan batasan seribu kutipan dalam urutan daftar peringkat dan menghasilkan sebuah metrics yang dapat digunakan untuk menganalisis dampak artikel penulis dan dampak sebuah jurnal (Lukman, et al., 2019).

Pada tahun 2012, Pusat Pengembangan Informatika Nuklir yang sekarang menjadi Pusat Pendayagunaan Informatika dan Kawasan Strategis Nuklir (PPIKSN) BATAN telah mengembangkan portal jurnal berbasis web yang dalam pengelolaannya menggunakan aplikasi OJS. Portal ini memuat jurnal-jurnal ilmiah dari hasil penelitian para pelaku litbangyasa di lingkungan internal dan institusi luar BATAN. Dengan adanya portal tersebut, dapat bermanfaat untuk memantau sekaligus mengevaluasi kinerja setiap jurnal. Jumlah jurnal berbasis elektronik yang dimiliki BATAN sampai saat ini sebanyak 25 judul, dan semua termasuk dalam ketegori jurnal ilmiah. Seluruh jurnal dikelola dalam satu domain BATAN yang disimpan pada alamat situs http://jurnal.batan.go.id. Jumlah jurnal yang sudah terkareditasi sebanyak 8 judul jurnal dan memperoleh predikat level 2 pada portal Sinta dan telah terindeks pada google scholar. Untuk meningkatkan kualitas mutu jurnal, PPIKSN sebagai satminkal pengelolaan portal jurnal termasuk koordinasi penomoran DOI (digital object identifier) di BATAN selalu melakukan koordinasi dan evaluasi setiap tahun dalam hal teknis pengelolaan jurnal. Namun sampai saat ini belum pernah dilakukan kajian dan evaluasi untuk mengukur kinerja jurnal berbasis bibliometrik. Oleh karena itu, kajian ini dilakukan untuk mengevaluasi kinerja jurnal agar dapat memberikan masukan untuk dapat meningkatkan kualitas pengelolaan jurnal lebih optimal.

Berdasarkan latar belakang penelitian yang dijelaskan di atas, muncul 
masalah penelitian yaitu bagaimana mengukur kinerja jurnal terakreditasi di BATAN baik kuantitasi, kualitas dan dampak ilmiahnya. Beberapa pertanyaan menjadi rumusan masalah dalam kajian ini adalah: (1) Bagaimana keberkalaan jurnal-jurnal dalam menerbitkan artikel? (2) Jurnal mana yang paling produktif? (3) Bagaimana metriks sitasi jurnal? (4) Seberapa banyak jurnal disitasi oleh jurnal lain dan jurnal mana yang paling banyak disitasi? (5) Siapa penulis yang paling produktif dan paling banyak disitasi; (6) Bagaimana pemetaan kolaborasi antar penulis. Ruang lingkup kajian adalah 8 (delapan) judul jurnal ilmiah yang sudah terakreditasi yang tersedia pada portal jurnal BATAN. Sedangkan tujuan kajian ini adalah untuk menjawab pertanyaan pada rumusan masalah dalam kajian. Melalui kajian ini diharapkan dapat menjadi masukan untuk para pengelola jurnal dalam meningkatkan kualitas jurnal menjadi lebih baik.

\section{TINJAUAN PUSTAKA}

\section{Jurnal Ilmiah}

Jurnal ilmiah merupakan salah satu bentuk pemberitaan yang berisi karya ilmiah yang diterbitkan tecara teratur (regularity) dalam bentuk elektronik dan/atau tercetak. Jurnal ilmiah merupakan sumber informasi primer yang paling dibutuhkan, karena selain jadwal terbitnya teratur, berisi artikel yang ditulis oleh para peneliti untuk mempublikasikan hasil penelitiannya, dan di review oleh mitra bestari sesuai dengan bidang ilmunya (Elsera, 2018). Menurut Suryoputro, et al. (2012), jurnal ilmiah merupakan sebuah terbitan ilmiah yang dipublikasikan secara teratur oleh suatu organisasi profesi atau institusi yang menerbitkan artikel-artikel yang menghasilkan produk ilmiah dari penelitian dalam bidang ilmu tertentu yang dilakukan secara logis maupun berdasarkan pemikirian secara empiris.
Dapat disimpulkan bahwa jurnal ilmiah merupakan publikasi ilmiah yang diterbitkan secara berkala oleh suatu organisasi profesi atau institusi, menerbitkan artikel-artike baik dari hasil pengamatan maupun penelitian yang mengandung kebaruan dan inovasi dalam ilmu pengetahuan serta melalui proses review dalam bentuk elektronik dan/atau cetak.

Jurnal ilmiah memiliki fungsi yaitu keilmuan para peneliti dapat teregistrasi, dapat menyimpan setiap hasil temuan, memberikan pengakuan terhadap hasil kegiatan ilmiah yang sesuai dengan persyaratan yang telah ditentukan, membantu mendiseminasikan hasil kecendekiaan dan pengabdian kepada masyarakat serta melindungi hasil karya peneliti/cendekiawan. Agar dapat meningkatkan dan menghasilkan kualitas pengelolaan jurnal yang optimal adalah dengan cara mengikuti standar yang sesuai peraturan-peraturan yang telah ditetapkan pada akreditasi nasional (Junandi, 2018).

\section{Jurnal Ilmiah Terakreditasi}

Pengelola jurnal, dalam upaya meningkatkan kualitas mutu jurnal ilmiah, harus mengajukan akreditasi agar memperoleh status sebagai jurnal yang memiliki reputasi dan pengakuan secara resmi atas penjaminan mutu jurnal ilmiah. Jurnal yang telah terakreditasi artinya telah memenuhi prosedur yang sesuai dengan peraturan yang seharusnya mulai pengiriman naskah sampai ketepatan waktu dalam penerbitan jurnal. Terdapat berbagai syarat untuk mengajukan akreditasi jurnal ilmiah, minimal harus memiliki 8 kriteria yaitu jurnal: (1) telah memiliki nomor e-ISSN; (2) nama jurnal harus sesuai dengan permintaan ISSN yang sudah didaftarkan sebelumnya; (3) memiliki nomor identitas artikel DOI yang dapat dilakukan untuk melacak alamat referensi yang dirujuk; (4) menampilkan etika publikasi; (5) bersifat ilmiah dengan 
menerbitkan artikel yang secara nyata dapat memajukan ilmu pengetahuan, teknologi, dan/atau seni berdasarkan hasil penelitian, perekayasaan, dan/atau telaahan, mengandung inovasi baru dan/atau pemikiran yang orisinil serta tidak plagiat; (5) telah terbit minimal dua tahun secara berurutan dan terhitung mundur sejak tanggal atau bulan pengajuan akreditasi; (6) memiliki frekuensi penerbitan minimal dua kali dalam satu tahun dan terbit secara teratur; (7) jumlah artikel per terbitan minimal lima judul artikel; dan (8) telah memiliki profil pada pengindeks Google scholar khusus untuk jurnal.

Selain persyaratan tersebut di atas, terdapat sembilan kriteria dalam penilaian substansi artikel yang salah satunya adalah dampak ilmiah. Jumlah artikel yang disitasi oleh jurnal ilmiah lain menunjukkan dampak ilmiah sebuah jurnal yang harus dimiliki oleh jurnal yang akan mengusulkan akreditasi, faktor dampak, dan/atau nilai b-index yang telah memperoleh pengakuan dari lembaga pengindeks jurnal di tingkat internasional. Dampak ilmiah sebuah jurnal dapat diketahui dari profil jurnal di Google Scholar atau pengindeks lainnya yang memiliki metrik atau metode penghitungan sendiri. Sedangkan dalam penyebarluasanan harus memenuhi 3 kriteria penilaian yaitu (a) Jumlah kunjungan unik ke website jurnal yang dapat dilihat dari statistik pembaca yang mengunjungi jurnal; (b) pencantuman icon yang menyatakan bahwa jurnal telah terindeks pada pengindeks internasional DOAJ (directory of Open Access Journals) yaitu situs web yang merekap daftar jurnal dengan akses terbuka, dikelola oleh Infrastructure Services for Open Access, dan Google Scholar, dan sangat mebnatu untuk mendiseminasikan metadata artikel jurnal; (c) telah memiliki alamat/Identitas unik artikel menggunakan nomor digital object identifier (DOI) yang akan memudahkan dalam pemantauan proses sitasi dan indeksasi artikel.

\section{Open Access Jurnal}

Untuk membangun dan menumbuhkan kesadaran bagi pengguna jurnal ilmiah khususnya para peneliti, penulis atau akademisi dalam melakukan pengarsipan secara mandiri atau selfarchiving yang dapat membuka akses secara maksimal, muncul sebuah gerakan yang dinamakan dengan Open Access $(\mathrm{OA})$, akses terbuka yang membuka aksesnya seluas mungkin, serta mempublikasikan karya ilmiahnya pada jurnal OA (Irawan, et al., 2018). Akses terbuka merupakan sebuah model penerbitan ilmiah yang memungkinkan hasil penelitian dapat diakses secara gratis oleh pengguna melalui internet karena memiliki beberapa keunggulan peralatan digital yang mengubah mekanisme reproduksi dan pendistribusian berkas digital (Wibowo, 2019). Penerapan OJS untuk mengelola jurnal ilmiah secara daring dan akses terbuka memiliki banyak keunggulan, namun proses bisnis penerbitan artikel harus dilakukan secara online pada semua tahapan proses penanganan artikel mulai penerimaan artikel yang dikirimkan oleh penulis hingga dinyatakan terbit terekam pada sistem OJS. Untuk mendiseminasikan artikel yang sudah diterbitkan secara luas dan dapat diakses secara mudah dan gratis, pengelola jurnal harus berupaya untuk memasukkan terbitannya ke lembaga pengindeks yang menerima jurnal untuk diintegrasikan baik secara langsung seperti Google Scholar maupun melalui proses seleksi secara mudah seperti DOAJ (Lukman, et al., 2019). Salah satu kiteria untuk dapat terindeks pada Directory of Open Access Journals (DOAJ) adalah menyediakan akses terbuka untuk pembaca baik abstrak maupun naskah lengkapnya. Selain itu, ada beberapa kebijakan kebijakan akses terbuka yang harus ditunjukkan secara jelas pada situs jurnalnya pada bagian Aims and Scope (fokus dan ruang lingkup). Selain itu melengkapi situs OJS 
pada bagian Tentang Kami yang berisi kontak, Tim Editorial, Kebijakan, dll.

\section{Pengukuran Kijerja Jurnal}

Dari berbagai persyaratan yang harus dipenuhi untuk menjadi jurnal terakreditasi, maka dapat disimpulkan bahwa pengelolaan jurnal mulai dari pengiriman, penyuntingan, penelaahan, dan penerbitan naskah karya ilmiah dilaksanakan dalam suatu sistem aplikasi yang dinamakan jurnal ilmiah elektronik (e-journal). Selain itu, bisa digunakan untuk mengukur kinerja sebuah jurnal baik kuantitas maupun kualitas artikel pada sebuah jurnal. Adapun untuk mengukur dampak ilmiah sebuah jurnal dapat dilakukan dengan menghitung jumlah atau tingginya frekuensi sitasi oleh penulis dari jurnal lain atas tulisan yang telah diterbitkan, dan perannya sebagai acuan untuk melakukan kegiatan penelitian berikutnya. Untuk membuktikan hal ini dapat terlihat dengan telah diperolehnya pengakuan dari lembaga pengindeks jurnal di tingkat internasional dengan telah tercantumnya nilai $\mathrm{h}$-index yang menunjukkan adanya dampak ilmiah jurnal. Dampak ilmiah ini dapat terlihat dari profil jurnal di Google Scholar dan pengindeks lainnya yang memiliki metrik pengukuran atau penghitungan yang dinamis (Lukman, et al., 2019). Maryono dan Junandi (2012) memaparkan, metode penghitungan impact factor bukan hanya memandang dari jumlah artikel dan banyaknya jumlah sitasi, tetapi dapat diukur dari rasio jumlah sitasi dengan jumlah artikel yang akan memberikan pengaruh artikelartikel dari suatu jurnal terhadap kegiatan penulisan artikel pada jurnal yang sama. Bila hanya berpatokan pada ukuran besarnya jumlah artikel dan jumlah sitasi, maka jurnal kecil yang memiliki ruang lingkup yang spesifik tetapi sangat penting, tidak akan memperoleh tempat dalam peringkat jurnal. Oleh karena itu, peringkat berdasarkan besarnya impact factor, atau angka pengaruh tersebut sangat diperlukan.
Di dunia internasional, ada salah satu cara untuk mengukur kualitas sebuah karya ilmiah (jurnal ilmiah) yaitu dengan Impact Factor (IF). Angka impact factor merupakan standar penilaian yang dibuat oleh ISI (The Institute of Scientific Information) yang difungsikan untuk mengukur seberapa sering rata-rata artikel pada sebuah jurnal telah dikutip pada tahun tertentu (biasanya dalam waktu 2 tahun terakhir). Menurut Lukman, et al. (2019), saat ini telah banyak akses gratis ke mesin pencari yang terkait dengan kutipan seperti Google Scholar serta indikator bibliometrik inovatif yang membantu dalam menganalisis secara objektif produktivitas ilmiah jurnal, penulis atau institusi. Melalui bibliometrik inovatif, pengukuran menggunakan indikator baru tidak hanya mempertimbangkan jumlah kutipan tetapi juga pembobotan kutipan berdasarkan algoritma untuk mengukur pengaruh artikel atau penulis dalam komunikasi ilmiah dan pertumbuhan disiplin ilmu. Irawan et al. (2017) memberikan pendapat tentang beberapa hal yang terjadi dan perlu dilakukan agar artikel dirujuk oleh pembaca: (a) Pelaksanaan riset dan bahan baku makalah; (b) Proses penulisan dan penerbitan karya ilmiah yang memerlukan waktu yang cukup lama; (c) Diseminasi yang diperlukan untuk menjamin lebih banyak pihak mengetahui hasil riset melalui publikasi yang telah dihasilkan. Terdapat banyak cara agar artikel dapat diakses seperti mengunggah di repositori terbuka, membuat newsletter berisi daftar publikasi, hingga aktif menyebarkannya di media sosial. Selain itu, sementara menunggu artikel terbit, dapat mengunggah makalah preprint (pra peer review) pada blog, atau media sosial secara daring. Beberapa portal daring yang yang menyediakan indikator evaluasi penelitian ilmiah yang dipublikasikan pada jurnal ilmiah seperti SCImagoJR (SJR), Eigenfactor, PoP 
(Publish or Perish) Software dan Journal Metrics. PoP (Publish or Perish) adalah satu satunya yang dapat mengambil dan menyajikan data dari mesin pencari Google Scholar dan Microsoft Academic.

\section{Publish or Perish (PoP) Software}

Perangkat lunak PoP dikembangkan oleh Profesor Anne Wil Harzing pada tahun 2006 dan dapat diunduh dan secara gratis pada website di alamat situ https://harzing.com/resources/publishor-perish. Aplikasi ini dapat mengambil dan menganalisis informasi bibliografi dari Google Scholar dan Microsoft Academic Search untuk memperoleh kutipan mentah dengan batasan maksimal seribu kutipan dalam urutan daftar peringkat. Hasil penelusuran dapat disimpan dalam file *.ris, ${ }^{*} \operatorname{csv}$ dan lainnya yang dapat dijalankan dengan aplikasi lain seperti aplikasi VOSviewer untuk memetakan kolaborasi penulis atau trend subyek suatu jurnal. Selain itu dapat disimpan dalam format lain seperti Microsoft excel yang dapat digunakan untuk melakukan tabulasi data sesuai kebutuhan (Harzing, 2010). Publish or Perish Software menghasilkan sebuah metriks yang dapat digunakan untuk menganalisis dampak artikel penulis dan dampak sebuah jurnal.

Bila dibandingkan dengan SCImagoJR (SJR), Eigenfactor, dan

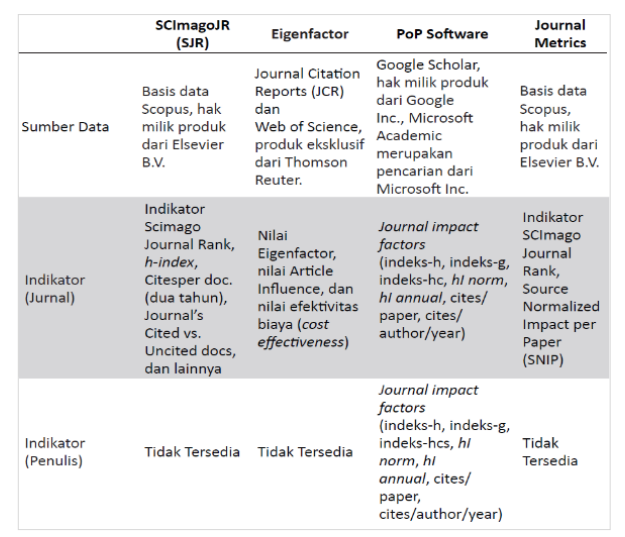

Gambar 1 Perbandingan Fitur SJR, eigen Factor, Publish or Perish Software dan Journal Metrics Sumber: Lukman, et al. (2019)
Journal Metrics, maka hanya aplikasi PoP yang dapat mengambil data dari Google Scholar dan menghasil metriks yang dapat mengukur indikator jurnal dan penulis yang dapat dilihat pada Gambar 1. Sedangkan pada Gambar 2 ditampilkan kemampuan PoP dalam melakukan penelusuran pada Google Scholar Query dengan pencarian melalui penulis, nama publikasi, judul artikel, frase dan lainnya. Metriks yang dihasilkan oleh Aulianto, et al., (2019) menjelaskan antara lain: jumlah total artikel dan jumlah sitasi; sitasi rata-rata per artikel, sitasi per penulis, dan sitasi per tahun; $b$-indeks dan parameter terkait g-index; tiga variasi h-index individu; peningkatan tahunan rata-rata dalam $h$ index individu; tingkat kutipan tertimbang usia; analisis jumlah penulis per artikel. Aplikasi ini dirancang untuk membantu penulis mempresentasikan dampak penelitian meskipun hanya memiliki sedikit kutipan, memutuskan jurnal mana yang akan disubmit, mempersiapkan wawancara kerja, melakukan tinjauan literatur, melakukan penelitian bibliometrik, dan lainnya. Hasilnya dapat disalin ke clipboard Windows (untuk dijalankan ke aplikasi lain seperti untuk pemetaan menggunakan aplikasi Vosviewer) atau disimpan ke berbagai format output (untuk referensi di masa mendatang atau analisis lebih lanjut (Harzing, 2011).

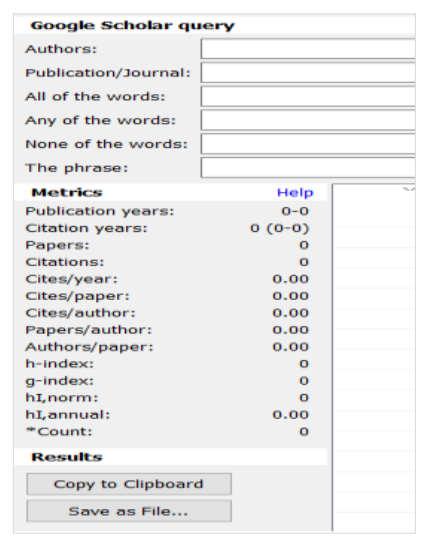

Gambar 2 Google Scholar Query dan Metrics pada Publish or Perish Software 


\section{Penelitian Terdahulu}

Penelitian tentang pengukuran kinerja jurnal ilmiah pernah dilakukan oleh Natakusumah (2016) melakukan penelitian dengan judul Bibliometric Analysis of the Inkom Journal (Analisis Bibliometrik Jurnal Inkom). Hasil penelitian menunjukkan diperolehnya peningkatan kualitas artikel ilmiah yang memiliki kejelasan dalam posisi penelitian yang didukung oleh berbagai jenis sumber literatur yang sesuai yang digunakan sebagai referensi pada tahun 2012, diperoleh jumlah sitasi sebanyak 197 sitasi dari 17 artikel. Hasil ini memperlihatkan terjadinya kenaikan jumlah sitasi dari tahun sebelumnya dengan rata-rata sitiran per artikel adalah 11 .

Kajian pernah dilakukan oleh Aulianto, et.al pada tahun 2019 dengan judul makalah Pemanfaatan aplikasi "publish or perish" atau PoP sebagai alat analisis sitasi pada jurnal kajian komunikasi Universitas Padjadjaran. Tujuan kajian tersebut adalah untuk menganalisis kualitas jurnal yang dilihat dari dampak ilmiah yang dihasilkan berupa angka sitasi yang dicapat dengan menggunakan alat sitasi PoP sehingga diketahui metriks sitasi yang dimiliki. Angka metriks sitasi jurnal kajian komunikasi ditelusuri menggunakan sumber data google scholar query untuk dapat menganalisis angka-angka sitasi pada suatu jurnal ilmiah yang hasilnya disajikan dalam bentuk metriks dampak. Analisis yang dihasilkan lengkap dan dapat dijadikan bahan evaluasi terhadap kualitas artikel per penulis, maupun kualitas jurnal secara keseluruhan.

Selanjutnya Aulianto, et.al pada tahun yang sama (2019) melakukan kajian dengan judul Citations Analysis of Jurnal Kajian Informasi \& Perpustakaan Universitas Padjadjaran, Indonesia. Tujuan penelitian tersebut adalah untuk mengetahui perkembangan Journal of Information \& Library Study (JKIP) yang telah diterbitkan sejak 2013, analisis kutipan, termasuk distribusi artikel setiap tahun, pola kepengarangan, jumlah kutipan tertinggi dan bentuk visualisasi. Metode yang digunakan adalah analisis bibliometrik, data tersebut diproses dan dianalisis menggunakan Microsoft Excel, PoP dan VOSviewer. Hasil penelitian menunjukkan bahwa sejak tahun 2017, kualitas artikel telah menjadi fokus JKIP dilihat dari jumlah artikel yang diterbitkan secara konsisten dalam jumlah dan memiliki jumlah kutipan 190 dan tertinggi untuk satu judul artikel memiliki 9 kutipan.

Perbedaaan yang dilakukan dalam kajian ini adalah fokus dan ruang lingkup kajian, yaitu untuk mengevaluasi jurnaljurnal yang sudah terakreditasi di BATAN menggunakan aplikasi PoP dan VOSviewer untuk memetakan kolaborasi antar penulis.

\section{Metodologi Penelitian}

Metode yang digunakan dalam kajian ini adalah bibliometrik dan analisis deskripsi. Menurut Morant, et al. (2017), analisis bibliometrik memungkinkan untuk mengetahui masa lalu, memahami kemajuan saat ini dan meningkatkan penelitian di masa depan. Natakusumah (2016) menyatakan bahwa bibliometrik adalah penggunaan metode matematika dan statistik dalam buku atau media komunikasi lainnya. Studi bibliometrik melibatkan analisis kualitatif publikasi atau satu set publikasi, dengan melihat bibliografi, kepengarangan, tahun publikasi, kutipan, gambar, dan grafik, dll. Pengolahan data diproses menggunakan Microsoft Excel untuk tabulasi data. Untuk mendapatkan hasil analisis kutipan dilakukan menggunakan aplikasi Publish or Perish dan VOSviewer untuk menunjukan visualisasinya. Populasi kajian adalah jurnal yang diterbitkan pada portal jurnal BATAN, sedangkan yang dijadikan sampel adalah jurnal yang terakreditasi sebanyak 8 judul jurnal. Basis data yang digunakan dalam kajian ini diperoleh melalui halaman portal jurnal BATAN di 
http://jurnal.batan.go.id. Semua jurnal terakreditasi mendapat peringkat S2 dari Portal Sinta Science and Technology Index.

Pengumpulan data dilakukan pada tanggal 12 April 2020. Untuk mengetahui dampak jurnal dilakukan dari database online Google Scholar dan pencarian data menggunakan aplikasi PoP dengan menuliskan judul jurnal terakreditasi dan e-ISSN pada google scholar query. Setelah menekan tombol lockup, diperoleh hasil pencarian dalam bentuk metrics seperti pada Gambar 1. Selanjutnya data yang diperoleh dicek ulang untuk meyakinkan bahwa dokumen tersebut benar diterbitkan oleh jurnal yang dicari, dan untuk memperoleh jumlah artikel yang valid, karena ada dokumen seperti cover dan daftar isi, halaman belakang dan lainnya. Selanjutnya data tersebut dapat di di salin ke dalam microsoft excel untuk dikelompokkan dan ditabulasi sesuai dengan kebutuhan. Penyajian data menggunakan tabel (tabulasi) sesuai dengan tujuan kajian untuk menjelaskan hasil. Untuk memvisualisasikan kolaborasi penulis dilakukan dengan menggunakan aplikasi VOSviewer dari data yang sudah diexport dalam file ${ }^{*}$ ris.

\section{PEMBAHASAN}

\section{Distribusi Artikel Dan Keberkalaan Jurnal}

Berdasarkan hasil rekapitulasi data pada 8 (delapan) jurnal terakreditasi, diperoleh distribusi atau sebaran jumlah judul artikel sejak tahun 1999-2020 dan keberkalaan jurnal dalam menerbitkan artikel seperti ditampilkan pada Tabel 1 . Secara keseluruhan jurnal yang sudah terakreditasi terbit secara teratur. Semua jurnal sudah terindeks pada Google Scholar namun hanya 4 jurnal yang sudah terindeks pada DOAJ seperti ditampilkan pada Tabel 2. Pencantuman di pengindeks internasional bertujuan mendiseminasikan metadata artikel jurnal ilmiah agar lebih mudah ditemukan. Oleh karena itu jurnal yang belum terindeks pada DOAJ agar memasukkan jurnalnya dengan mempersiapkan persyaratan sesuai dengan kriteria yang telah ditentukan.

Tabel 1 Sebaran jumlah artikel pada 8 jurnal terakreditasi di tahun 1999-2020

\begin{tabular}{|c|l|c|c|c|c|c|c|c|c|}
\hline No. & Nama Jurnal & $1999-2014$ & 2015 & 2016 & 2017 & 2018 & 2019 & 2020 & Jumlah \\
\hline 1 & J. Sains Materi Indonesia & 622 & 31 & 28 & 28 & 28 & 21 & 0 & 758 \\
\hline 2 & J. Pengembangan Energi Nuklir & 195 & 14 & 14 & 14 & 14 & 13 & 0 & 264 \\
\hline 3 & J. Sains dan Teknologi Nuklir Indonesia & 179 & 10 & 10 & 10 & 10 & 10 & 1 & 230 \\
\hline 4 & Urania J. Ilmiah Daur Bahan Bakar Nuklir & 138 & 18 & 18 & 18 & 18 & 18 & 0 & 228 \\
\hline 5 & Ganendra Majalah Iptek Nuklir & 147 & 12 & 10 & 12 & 11 & 11 & 0 & 203 \\
\hline 6 & J. Ilmiah Aplikasi Isotop Dan Radiasi & 123 & 14 & 14 & 14 & 14 & 14 & 0 & 193 \\
\hline 7 & J. Teknologi Reaktor NuklirTri Dasa Mega & 75 & 15 & 15 & 15 & 16 & 15 & 5 & 156 \\
\hline 8 & Eksplorium & 45 & 10 & 11 & 14 & 14 & 14 & 0 & 108 \\
\hline
\end{tabular}

Sumber: Data hasil penelitian (Noeraida, 2020)

Tabel 2 Status pencantuman pengindeks 8 Jurnal terakreditasi di BATAN

\begin{tabular}{|c|l|c|c|}
\hline No. & Nama Jurnal & DOAJ & Google Scholar \\
\hline 1 & Jurnal Ilmiah Aplikasi Isotop dan Radiasi (JIAIR) & $\mathrm{x}$ & 8 \\
\hline 2 & Jurnal Teknologi Reaktor Nuklir -Tri Dasa Mega (J.TDM) & $\mathrm{v}$ & 7 \\
\hline 3 & Ganendra Majalah Iptek Nuklir (GANENDRA) & $\mathrm{v}$ & 6 \\
\hline 4 & Eksplorium (EKSPLORIUM) & $\mathrm{v}$ & 6 \\
\hline 5 & Jurnal Sains dan Teknologi Nuklir Indonesia (JSTNT) & $\mathrm{x}$ & 6 \\
\hline 6 & Jurnal Pengembangan Energi Nuklir (JPEN) & $\mathrm{x}$ & 5 \\
\hline 7 & Urania Jurnal Ilmiah Daur Bahan Bakar Nuklir (URANIA) & $\mathrm{x}$ & 4 \\
\hline 8 & Jurnal Sains Materi Indonesia (JUSAMI) & 3 \\
\hline
\end{tabular}

Sumber: Data hasil penelitian (Noeraida, 2020) 


\section{Produktivitas Jurnal}

Jurnal Sains Materi Indonesia merupakan jurnal yang paling produktif mengasilkan artikel sebanyak 758 judul sejak tahun 2000-2019, namun jumlah judul tidak merata karena menerbitkan edisi khusus, dan ada juga yang diperoleh melalui seminar. Jurnal yang lebih dulu terbit adalah JPEN sejak tahun 19992019, jumlah judul adalah 264 judul dan jumlah artikel cenderung stabil. Sedangkan jurnal yang paling sedikit jumlah artikelnya adalah EKSPLORIUM dengan jumlah artikel 108 judul sejak tahun 2011-2019, dan data selengkapnya dapat dilihat pada Gambar 3. Secara umum semua jurnal menerbitkan jumlah artikel dengan konsisten. Berdasarkan hasil kajian, ditemukan perbedaan nilai h-index dari Google Scholar dengan hasil pencarian menggunakan aplikasi PoP seperti ditampilkan pada Gambar 4. Perbedaan nilai $h$-index pada scholar dengan h-index pada aplikasi PoP dapat disebabkan pada beberapa jurnal belum menginput semua artikel yang telah dipublikasikan. Selain itu beberapa penulis belum memiliki profile pada google scholar.

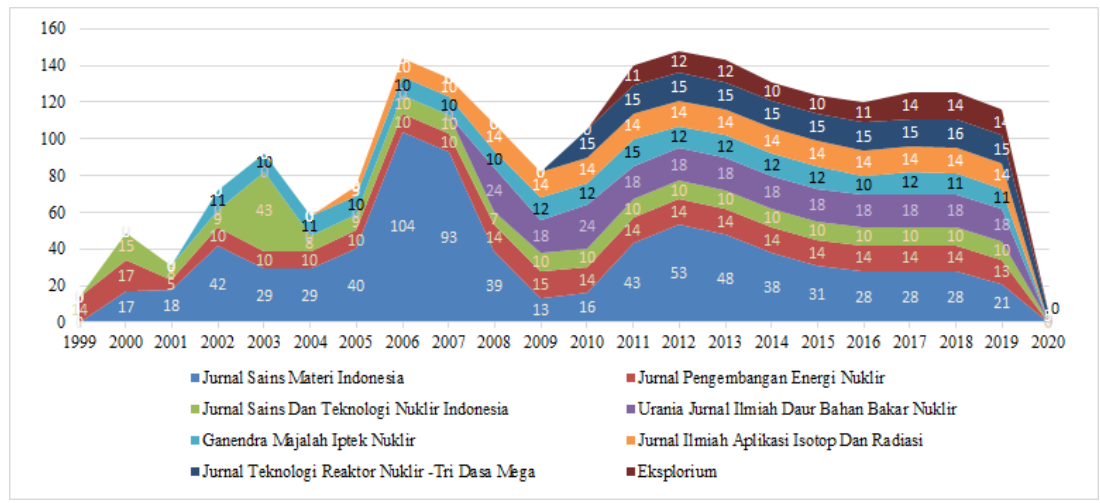

Gambar 3 Sebaran jumlah artikel pada 8 jurnal terakreditasi tahun 1999-2020 Sumber: Data hasil penelitian (Noeraida, 2020)

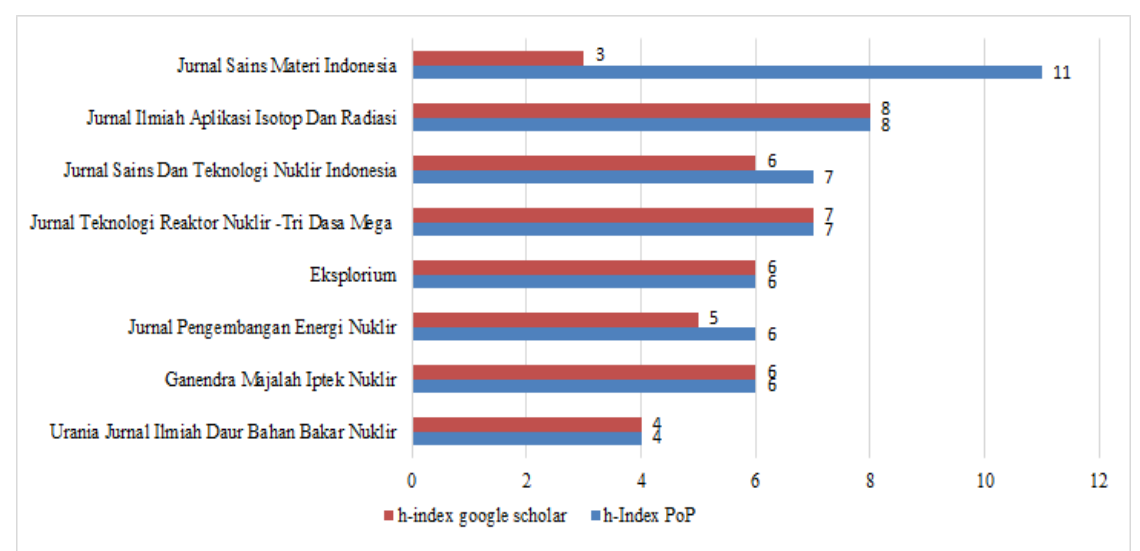

Gambar 4 Perbandingan antara hasil h-index google scholar dan PoP Sumber: Data hasil penelitian (Noeraida, 2020)

\section{Metriks sitasi 8 jurnal terakreditasi}

Untuk mengetahui dampak jurnal bagi kemajuan keilmuan dapat diidentifikasi melalui analisis metriks sitasi yang dimiliki oleh setiap jurnal ilmiah.
Berdasarkan data pada Tabel 3 yang diperoleh dari hasil analisis menggunakan aplikasi PoP terhadap 8 jurnal terakreditasi di BATAN maka diperoleh metrics sebagai berikut: tahun publikasi 
(publication years), merupakan tahun terbit jurnal yang tercantum dalam situs online jurnal OJS, dan ditemukan mulai tahun terbitan 1999-2020. Tahun sitasi (citation years) adalah hasil sitasi yang dilakukan oleh penulis lain sejak tahun 1999-2020. Jumlah artikel (papers) yang terbit pada tahun 1999-2020. Jumlah sitasi (citations). Jurnal yang paling banyak jumlah artikel dan disitasi adalah JUSAMI yaitu 674 artikel dan disitasi sebanyak 744 kali. Jumlah sitasi pertahun jurnal (cites/year), sitasi perpenulis (cites/author), artikel per penulis (papers/author) dan penulis perartikel (author/paper).

Suatu terbitan mempunyai indeks yang digunakan untuk mengukur produktifitas dan dampak suatu artikel yang dipublikasikan oleh para penulis, peneliti maupun ilmuwan yang disebut dengan h-index. Perhitungan g-index adalah jumlah rata-rata dikutip secara keseluruhan, setelah diurutkan sampai angka g. $\mathrm{H}$-index dan g-index merupakan angka pada urutan dokumen ke, setelah dokumen diurutkan berdasar jumlah dikutip. Pada laman Harzing.com, dijelaskan bahwa hI,norm adalah h-index individu yang diperoleh dari menormalkan jumlah kutipan untuk setiap artikel dengan membagi jumlah kutipan dengan jumlah penulis untuk artikel itu, dan kemudian menghitung hindex dari jumlah kutipan yang dinormalisasi. Sedangkan hI, annual (hla) merupakan angka yang diperoleh dari hl, norm dibagi usia akademik (jumlah tahun yang berlaku sejak publikasi pertama) (Aulianto et al., 2019). Pada Tabel 3, terlihat bahwa pada 8 jurnal terakreditasi paling tinggi memiliki $\mathrm{h}$ index 11 dan g-index 16, dan hI, norm paling tinggi 7 adalah JUSAMI. Sedangkan yang memiliki hI,annual paling tinggi 0,75 adalah JTDM. Mengacu pada Permenristekdikti Nomor 9 Tahun 2018 untuk penilaian dampak ilmiah yang diukur dengan jumlah artikel yang disitasi, maka delapan jurnal tersebut termasuk dalam kategori jumlah sitasi tinggi dan tidak ada yang memiliki sitasi jurnal 0 (nol).

Tabel 3 Hasil Analisis menggunakan Publish or Perish 8 jurnal terakreditasi

\begin{tabular}{|c|c|c|c|c|c|c|c|c|c|c|c|c|}
\hline No. & Nama Jurnal & $\begin{array}{c}\text { Tahun } \\
\text { Publikasi }\end{array}$ & $\begin{array}{l}\text { Tahun } \\
\text { Sitasi }\end{array}$ & $\begin{array}{l}\text { Jumlah } \\
\text { tahun } \\
\text { sitasi }\end{array}$ & $\begin{array}{l}\text { Jumlah } \\
\text { Artikel }\end{array}$ & $\begin{array}{l}\text { Jumlah } \\
\text { sitasi }\end{array}$ & $\begin{array}{c}\text { Sitasi } \\
\text { per } \\
\text { tahun }\end{array}$ & $\begin{array}{c}\text { Sitasi } \\
\text { per } \\
\text { artikel }\end{array}$ & $\begin{array}{l}\text { sitasi/ } \\
\text { penulis }\end{array}$ & $\begin{array}{c}\text { Artikel/ } \\
\text { penulis }\end{array}$ & $\begin{array}{l}\text { Penulis } \\
\text { /paper }\end{array}$ & $\begin{array}{c}\mathrm{h}- \\
\text { Index }\end{array}$ \\
\hline 1 & JUSAMI & $2000-2019$ & $2000-2020$ & 20 & 674 & 744 & 37,2 & 1,1 & 300,51 & 290,33 & 2,88 & 11 \\
\hline 2 & J IAIR & $2010-2019$ & $2010-2019$ & 15 & 189 & 321 & 32,10 & 1,7 & 180,94 & 100,77 & 2,45 & 8 \\
\hline 3 & JSTNI & $2000-2020$ & $2000-2020$ & 20 & 227 & 246 & 12,3 & 1,08 & 145,7 & 128,68 & 2,39 & 7 \\
\hline 4 & JTDM & $2012-2020$ & $2012-2020$ & 8 & 156 & 236 & 29,5 & 1,51 & 139,22 & 86,73 & 2,36 & 7 \\
\hline 5 & JPEN & $1999-2020$ & $1999-2020$ & 21 & 273 & 209 & 9,95 & 0,77 & 113,62 & 164,32 & 2,13 & 6 \\
\hline 6 & GANENDRA & $2002-2019$ & $2002-2020$ & 18 & 152 & 155 & 8,61 & 1,02 & 91,7 & 84,37 & 2,28 & 6 \\
\hline 7 & URANIA & $2013-2019$ & $2013-2020$ & 7 & 197 & 137 & 19,57 & 0,7 & 70,66 & 99,05 & 2,55 & 4 \\
\hline 8 & EKSPLORIUM & $2011-2019$ & $2011-2020$ & 9 & 104 & 140 & 15,56 & 1,35 & 59,07 & 45 & 2,86 & 6 \\
\hline
\end{tabular}

Sumber: Data hasil penelitian (Noeraida, 2020)

\section{Analisis Sitasi Jurnal menggu- nakan aplikasi PoP}

Semua jurnal terakreditasi yang sudah terindeks Google Scholar dapat diambil jumlah artikel yang disitasi jurnal lain menggunakan aplikasi PoP. Jurnal yang memiliki jumlah artikel dan disitasi paling banyak adalah Jurnal Sains Materi
Indonesia sebanyak 674 judul, diikuti Jurnal Pengembangan Energi Nuklir 273 judul dan yang paling sedikit adalah jurnal Eksplorium sebanyak 104 judul yang selengkapnya dapat dilihat pada Gambar 5. Namun metode penghitungan impact factor bukan hanya memandang dari jumlah artikel dan 
banyaknya jumlah sitasi, tetapi pengaruh artikel-artikel dari suatu jurnal terhadap kegiatan penulisan artikel pada jurnal yang sama, diukur dari rasio jumlah sitasi dengan jumlah artikel (Maryono, 2012). Maka yang paling tinggi rasio jumlah sitasinya adalah Urania Jurnal Ilmiah
Daur Bahan Bakar Nuklir 1,44 diikuti Jurnal Pengembangan Energi Nuklir 1,31. Sedangkan yang paling kecil adalah Jurnal Ilmiah Aplikasi Isotop dan Radiasi 0,59 yang data selengkapnya dapat dilihat pada Tabel 4.

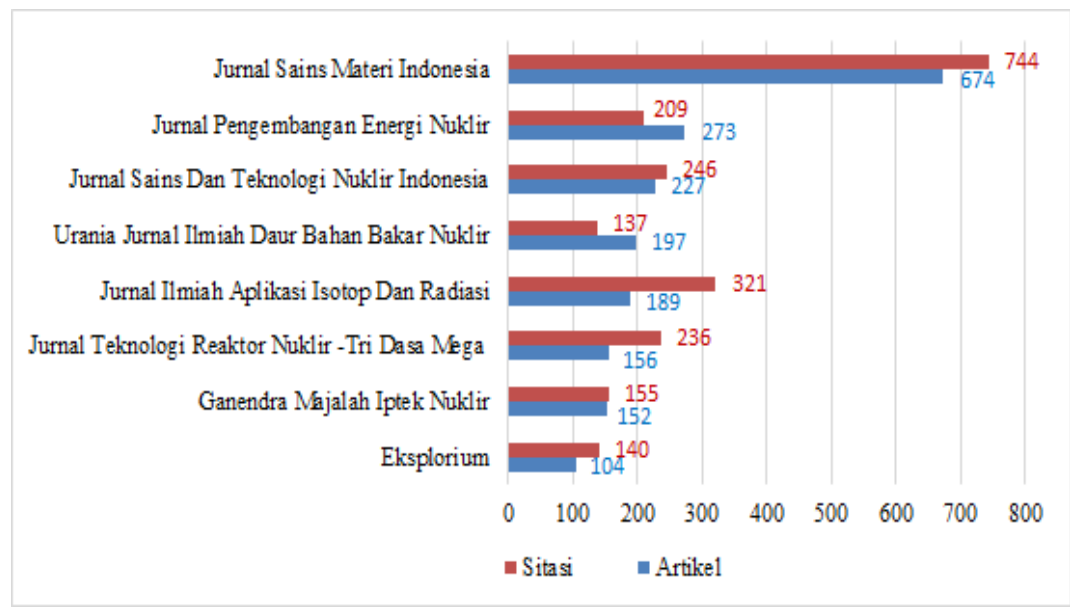

Gambar 5 Perbandingan jumlah artikel dan artikel yang disitasi dari data PoP Sumber: Data hasil penelitian (Noeraida, 2020)

Tabel 4 Jumlah Artikel, Sitasi dan Rasio Jurnal Terakreditasi

\begin{tabular}{clccc}
\hline No. & Nama Jurnal & Jumlah artikel & Jumlah Sitasi & Ratio \\
\hline 1 & URANIA & 197 & 137 & 1,44 \\
2 & JPEN & 273 & 209 & 1,31 \\
3 & GANENDRA & 152 & 155 & 0,98 \\
4 & JSTNT & 227 & 246 & 0,92 \\
5 & JUSAMI & 674 & 744 & 0,91 \\
6 & EKSPLORIUM & 104 & 140 & 0,74 \\
7 & TDM & 156 & 236 & 0,66 \\
8 & JIAIR & 189 & 321 & 0,59 \\
\hline
\end{tabular}

Sumber: Data hasil penelitian (Noeraida, 2020)

\section{Penulis yang paling produktif dan paling banyak disitasi}

Dari 2.140 artikel yang dipublikasikan pada 8 jurnal terakreditasi, diperoleh 15 peringkat penulis yang paling produktif dan paling banyak disitasi artikelnya yang ditampilkan pada Tabel 5. Penulis yang paling produktif adalah Adi, Wa sebanyak 37 judul dipublikasikan pada JUSAMI, diikuti oleh Susiati, $H$ sebanyak 31 dipublikasikan pada JPEN dan Mujamilah 28 judul dipublikasikan pada
JUSAMI, dan lainnya. Namun Artikel yang paling banyak disitasi adalah artikel yang ditulis oleh $\mathrm{S}$ Hartanto dan Ratnawati $\mathrm{R}$ yang disitasi sebanyak 39 kali dipublikasikan pada JUSAMI dengan judul artikel "Pembuatan Karbon Aktif dari Tempurung Kelapa Sawit Dengan Metode Aktivasi Kimia". Artikel tersebut merupakan temuan atau inovasi yang memberikan manfaat langsung kepada masyarakat sehingga banyak disitasi. Hasil ini menunjukan bahwa banyaknya jumlah artikel tidak berbanding lurus 
dengan jumlah sitasi. Semakin tinggi angka sitasi maka semakin bermanfaat artikel yang ditulis dan diterbitkan, hal ini dapat dijadikan bahan evaluasi oleh pengelola jurnal bahwa kualitas artikel yang diterbitkan sudah baik (Aulianto, et al., 2019).

\section{Pemetaan Kolaborasi Antar Penulis}

Untuk mengetahui pemetaan kolaborasi antar penulis, dalam kajian ini dilakukan visualisasi menggunakan aplikasi VOSviewer dari data yang disimpan dengan file * ris. Untuk memperoleh pemetaan secara keseluruhan, dilakukan pemetaan pada 8 jurnal secara sekaligus dengan menggabungkan data dan kriteria jumlah dokumen penulis minimal 5 judul. Diperoleh hasil sebanyak 205 penulis yang terbagi dalam 16 kelompok kluster dengan warna yang berbeda dan yang memenuhi persyaratan 169 penulis seperti ditunjukan pada Gambar 6. Hasil visualisasi menunjukkan bahwa terdapat kolaborasi antar penulis dari ke 8 jurnal, semakin besar lingkaran semakin sering penulis berkolaborasi. Jaringan antara penulis yang terhubung menunjukan bahwa penulis berkolaborasi untuk bekerjasama dalam melakukan penelitian. Setiap penulis memiliki hubungan dengan penulis lain, semakin kuat hubungan antara penulis, semakin besar lingkaran yang terjadi. Kolaborasi antar penulis terjadi karena ada kesamaan dalam subjek penelitian, meskipun berbeda unit kerja atau jabatan fungsionalnya.

Tabel 5 Peringkat 15 penulis yang memiliki angka sitasi dan artikel paling banyak

\begin{tabular}{cllclllc}
\hline \multicolumn{4}{c}{ Jumlah Artikle Penulis } & & & & Jumlah Sitasi Penulis \\
\hline No. & Jurnal & Penulis & Jumlah & No. & Jurnal & Penulis & Sitasi \\
\hline 1 & JUSAMI & Adi, wa & 37 & 1 & JUSAMI & S Hartanto, R Ratnawati & 39 \\
2 & JPEN & Susiati, h & 31 & 2 & JUSAMI & R Kartini, et al. & 25 \\
3 & JUSAMI & Mujamilah, $\mathrm{m}$ & 28 & 3 & JUSAMI & AH Saputra, et al. & 23 \\
4 & JUSAMI & Sudirman, s & 27 & 4 & JUSAMI & RB Sampurno & 22 \\
5 & JUSAMI & Ridwan, r & 26 & 5 & JUSAMI & A Yulianto, et al. & 22 \\
6 & JPEN & Susilo, ysb & 26 & 6 & JUSAMI & P Irasari, N Idayanti & 20 \\
7 & JUSAMI & Sukirman, e & 25 & 7 & PAIR & A Kurniawati & 21 \\
8 & JUSAMI & Winatapura, ds & 24 & 8 & JUSAMI & EF Purnama, et al. & 15 \\
9 & JPEN & Sriyana, s & 23 & 9 & JSTNI & TR Mulyaningsih & 18 \\
10 & JPEN & Alimah, s & 20 & 10 & PAIR & Y Warastuti, B Abbas & 15 \\
11 & JUSAMI & Kartini, e & 18 & 11 & JUSAMI & S Safni, F Sari, et al. & 15 \\
12 & PAIR & Sidauruk, p & 18 & 12 & URANIA & S Kuntjoro, PM Udiyani & 14 \\
13 & URANIA & Anggraini, d & 17 & 13 & PAIR & A Arwin, HI Mulyana, et al. & 14 \\
14 & JPEN & Lumbanraja, sm & 17 & 14 & TDM & S Dibyo, ID Irianto & 13 \\
15 & JPEN & Salimy, dh & 17 & 15 & URANIA & S Suwoto, H Adrial, Z Zuhair & 13 \\
\hline
\end{tabular}

Sumber: Data hasil penelitian (Noeraida, 2020) 


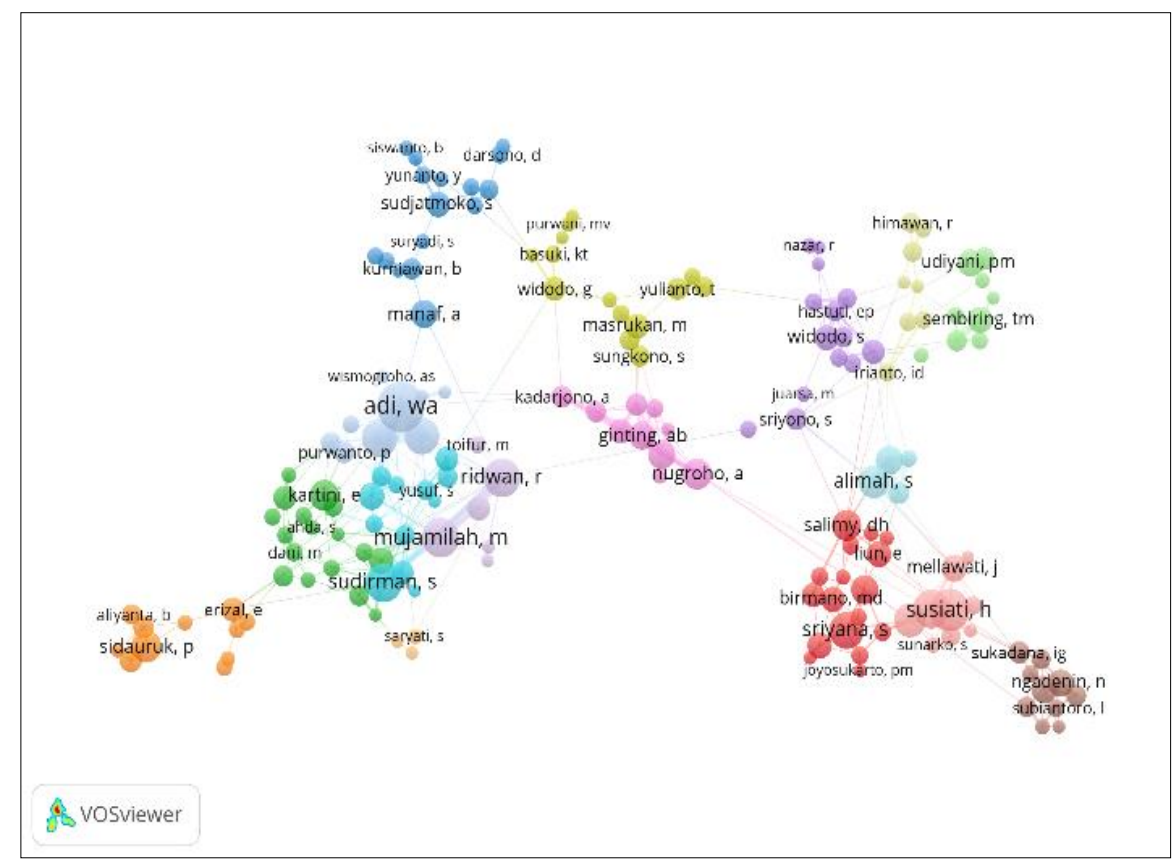

Gambar 6 Visualisasi kolaborasi antar penulis dari 8 jurnal dengan kriteria jumlah minimal 5 dokumen

Sumber: Data hasil penelitian (Noeraida, 2020)

\section{DISKUSI}

Berdasarkan hasil kajian yang sudah diuraikan sebelumnya, seluruh jurnal yang telah terkareditasi di BATAN memiliki kinerja yang memadai. Selain itu juga telah menerapkan akses terbuka yang pengelolaannya menggunakan OJS, dapat diakses secara mudah dan tidak berbiaya. Meskipun beberapa jurnal belum terindeks pada DOAJ, namun beberapa pengelola jurnal menginput meta data artikel ke repository BATAN. Sementara para peneliti juga menginput artikel ke profile pada google scholar, academia edu, research gate dan lainnya. Selain itu, PPIKSN juga menginput meta data jurnal-jurnal yang telah diterbitkan ke basis data INIS (International Nuclear Information System) agar dapat diakses oleh peneliti dari berbagai negara. Hal ini membantu dalam mendiseminasikan hasil penelitian yang dipublikasikan dari setiap jurnal. Sejalan dengan itu, Irawan, et al. (2017) memberikan pendapat tentang beberapa hal yang terjadi dan perlu dilakukan agar artikel dirujuk oleh pembaca: (a) Pelaksanaan riset dan bahan baku makalah; (b) Proses penulisan dan penerbitan karya ilmiah yang memerlukan waktu yang cukup lama; (c) Diseminasi yang diperlukan untuk menjamin lebih banyak pihak mengetahui hasil riset melalui publikasi yang telah dihasilkan. Dalam prakteknya ada banyak cara, mengunggahnya secara daring di repositori terbuka, membuat newsletter berisi daftar publikasi, hingga aktif menyebarkannya di media sosial. Repositori Ilmiah Nasional (RIN) yang dikelola oleh PDDI LIPI juga merupakan salah satu cara untuk mempublikasikan hasil penelitian selain untuk menyimpan data para peneliti, namun di BATAN sampai saat ini belum tersosialisasikan secara optimal. Hasil kajian ini dapat memberikan masukan kepada para pengelola jurnal untuk meningkatkan pengelolaannya baik kuantitas maupun kualitas serta pemrosesannya yang lebih efisien dan tepat waktu. Selain itu, penggunaan aplikasi PoP sangat bermanfaat untuk mengevaluasi, melihat sitasi dan merangking jurnal-jurnal yang terindeks di Google Scholar. 


\section{KESIMPULAN}

Berdasarkan hasil kajian dapat disimpulkan bahwa dalam pengukuran kinerja jurnal ilmiah terakreditasi, selain keberkalaan artikel yang terbit tepat waktu dan jumlah artikel yang terpenuhi, juga sudah menerapkan jurnal dengan akses terbuka. Untuk meningkatkan kualitas artikel harus lebih diperhatikan yang dapat dilakukan pada awal seleksi penerimaan makalah. Hal ini berkaitan kualitas publikasi yang dilihat dari dampak ilmiah yang dihasilkan yaitu berupa angka sitasi yang dicapai. Bila kualitas artikel baik maka akan banyak disitasi oleh penulis dari jurnal lain. Jurnal yang belum terindeks di DOAJ harus berupaya untuk memasukkan ke pengindeks tersebut, agar dapat diakses lebih luas baik abstrak maupun artikel lengkapnya. Ditemukan beberapa jurnal jurnal yang belum menginput seluruh artikel ke dalam profile jurnal pada Google Scholar. Untuk meningkatkan akses artikel secara luas, pengelola jurnal dapat menginput metadata artikel pada penyimpanan lain seperti repositori institusi, neliti.com dan lainnya. Jumlah kutipan yang dicapai setiap jurnal sudah memadai. Jumlah artikel yang disitasi dalam suatu jurnal dalam periode tahun tertentu dalam bidang kajian ilmiah berkaitan dengan kualitas dan inovasi serta hasil riset yang menjadikan mutu publikasi yang tinggi. Semakin banyak artikel pada sebuah jurnal memiliki tingkat kutipan yang tinggi menunjukan lebih banyak tulisan mengutip artikel, kegunaan publikasi semakin terlihat. Penilaian dampak ilmiah yang diukur dengan jumlah artikel yang disitasi, pada 8 jurnal ilmiah terakreditasi di BATAN termasuk dalam kategori jumlah sitasi tinggi dengan rata rata sitasi jurnal pertahun 20,60. Diperoleh visualisasi jaringan antar penulis yang terhubung menunjukan bahwa penulis berkolaborasi untuk bekerjasama dalam melakukan penelitian. Hasil kajian ini diharapkan dapat dijadikan bahan evaluasi bagi para pengelola jurnal agar meningkatkan kualitas artikel per penulis, maupun kualitas jurnal secara keseluruhan. Saran dalam kajian ini adalah agar para pengelola jurnal meningkatkan kualitas artikel dengan melakukan seleksi dalam penerimaan dan mempercepat pemrosesan artikel dan menginput seluruh artikel ke pengindeks Google Scholar dan DOAJ dan repository BATAN agar dapat mendiseminasikan artikel secara optimal.

\section{UCAPAN TERIMA KASIH}

Penulis megucapkan terima kasih kepada kepala Subbidang Manajemen Pengetahuan Nuklir (MNP) Ibu Iis Sustini, A.Md. yang telah memberikan ijin dan dukungan untuk melakukan kajian ini.

\section{DAFTAR PUSTAKA}

Aulianto, D.R., Yusuf, P.M., dan Setianti, Y. (2019). Pemanfaatan aplikasi "publish or perish" sebagai alat analisis sitasi pada jurnal kajian komunikasi Universitas Padjadjaran. Disampaikan pada Seminar Nasional MACOM III Universitas Padjadjaran 2019. Diakses dari https://bit.ly/30XTpxo.

Aulianto, D.R., Yusuf, P.M., dan Setianti, Y. (2019). Citations Analysis of Jurnal Kajian Informasi \& Perpustakaan Universitas Padjadjaran, Indonesia. Library Philosophy and Practice (e-journal), Diakses dari https://digitalcommons.unl.edu/libphilpra c/2642/

Aulianto, D.R., Yusuf, P.M., dan Setianti, Y. (2019). Perkembangan ISSN Terbitan Berkala di Indonesia. Khizanah al-Hikmah: Jurnal Ilmu Perpustakaan, Informasi, dan Kearsipan 7(2). https://doi.org/10.24252/kah.v7i2a1.

Badan Tenaga Nuklir Nasional. (2019). Hilirisasi Hasil Litbang Iptek Nuklir Menjadi Titik Berat Kegiatan BATAN 5 Tahun Kedepan. Diakses dari https://bit.ly/30ZeEi6.

Elsera, M. (2018). Portal publikasi jurnal karya ilmiah program studi sistem informasi FTK Universitas Harapan berbasis web dengan metode fast (framework for the application of systems thinking). Buletin Utama Teknik. 14(1). Diakses dari

https://jurnal.uisu.ac.id/index.php/but/art icle/view/799. 
Suryoputro, G., Riadi, S., dan Sya’ban, A. (2012). Menulis Artikel untuk Jurnal Imiah. Jakarta; Uhamka Press.

Harzing, A. W. (2010). Publish or perish book: your guide to effective and responsible citation analysis. Melbourne Australia: Tarma Software Research Pty Ltd. Diakses dari https://harzing.com/publications/publishor-perish-book/pdf.

Harzing.com. (2011). Research in International Management. Diakses dari https:/ / harzing.com/resources/publish-orperish/tutorial/metrics/hi-norm-and-hia.

Irawan, Dasapta Erwin, et al. 2017. Penerapan Open Science di Indonesia agar Riset Lebih Terbuka, mudah diakses, dan meningkatkan dampak saintifik. Berkala Ilmu Perpustakaan dan Informasi 13(1) 25-36. DOI: http://10.22146/bip.17054.

Irawan, D.E., Abraham, J., Multazam, M.T., et al. (2018). Era baru publikasi di Indonesia: Status Jurnal Open Access di Directory of Open Access Journal (DOAJ). Berkala Ilmu Perpustakaan dan Informasi, 14(2), 133-147. https://doi.org/10.22146/bip.32920.

Junandi, S. 2018. Pengelolaan Jurnal Elektronik Bidang Perpustakaan Menuju Jurnal Terakreditasi. Pustabiblia: journal of library and information science 2 (1) 119-136. http://dx.doi.org/10.18326/pustabibilia.v2 I1.119-136.

Kementrian Riset Teknologi dan Pendidikan Tinggi. (2018). Permenristekdikti Nomor 9 Tahun 2018 tentang akreditasi jurnal ilmiah. Lukman. (2019). Pengelolaan dan Akreditasi Jurnal Nasional (Permenristekdikti nomor 9 tahun 2018), Kementerian Riset Teknologi dan Pendidikan Tinggi. Diakses dari http://kopertis3.or.id/v5/wpcontent/uploads/Lukman_Pengelolaandan-Akreditasi-Jurnal-IlmiahIndonesia 2019.pdf.

Lukman, Hidayat, D.S., Al-Hakim, S., dan Nadhiroh, I.M. (2019). Pengukuran Kinerja Riset: Teori dan Implementasi. Jakarta: LIPI Press. Diakses dari http://penerbit.lipi.go.id/data/naskah1562 653683.pdf.
Maryono dan Junandi, S. (2012). Tren Impact Factor, Produktivitas, dan Kolaborasi dalam Indonesian Journal of Chemistry. IPTEK-KOM 14 (2) 115-132. http://eprints.rclis.org/28093/.

Morant, G. A., et al. (2017). Mapping the Field: A Bibliometric Analysis of Green Innovation. Journal Sustainability 9(6) 1-15. https://doi.org/10.3390/su9061011.

Nashihuddin, W. \& Aulianto, D.R. (2016). Pengelolaan Terbitan Berkala Ilmiah sesuai Ketentuan Akreditasi: Upaya Menuju Jurnal Trakreditasi dan Bereputasi Internasional. Jurnal Pustakawan Indonesia 15(1-2) 83-98. Diakses dari http://journal.ipb.ac.id/index.php/jpi/artic le/view/16921.

Natakusumah, E. K. (2015). Bibliometric Analysis of the Inkom Journal (Analisis Bibliometrik Jurnal Inkom). Baca: Jurnal Dokumentasi dan Informasi 36(1), 1-10. https://doi.org/10.14203/j.baca.v36i1.199.

Noeraida, 2020. Laporan Pengkajian Analisis Pengukuran Kinerja Jurnal Ilmiah Terakreditasi di BATAN (studi bibliometrik). PPIKSNBATAN, Serpong.

Prasetyawan, Y.Y. (2018). Altmetrik sebuah Pengukuran Alternatif untuk Level Dampak dan Desiminasi Publikasi Ilmiah: Studi Kasus Mendeley. ANUV A: 2 (1): 19. https://ejournal2.undip.ac.id/index.php/a nuva/article/view/2731.

Prasetyawan, Y.Y. (2017). Perkembangan Open Access dan Kontribusinya bagi Komunikasi Ilmiah di Indonesia. ANUVA 1(2): 93-100. Diakses tanggal 22 April 2020 di https://ejournal2.undip.ac.id/index.php/a nuva/article/view/1909.

Wibowo, T.O. (2019). Strategi Pengelolaan Jurnal Akses Terbuka Menggunakan Open Journal System (OJS). Berkala Ilmu Perpustakaan dan Informasi 15(1): 101-113. https://doi.org/10.22146/bip.38504. 